\title{
Protein quality control: triage by chaperones and proteases
}

\author{
Susan Gottesman, ${ }^{1,3}$ Sue Wickner, ${ }^{1}$ and Michael R. Maurizi ${ }^{2}$ \\ Laboratories of ${ }^{1}$ Molecular Biology and ${ }^{2}$ Cell Biology, National Cancer Institute, Bethesda, Maryland 20892-4255 USA
}

Proteases and chaperones together serve to maintain quality control of cellular proteins. Both types of enzymes have as their substrates the variety of misfolded and partially folded proteins that arise from slow rates of folding or assembly, chemical or thermal stress, intrinsic structural instability, and biosynthetic errors. The primary function of classical chaperones, such as the Escherichia coli DnaK/Hsp70 and its cochaperones, Dnal and GrpE, and GroEL/Hsp60 and its cochaperone, GroES, is to modulate protein folding pathways, thereby preventing misfolding and aggregation, promoting refolding and proper assembly. Recent work has demonstrated that ATP-dependent proteases, as well as closely related proteins, have intrinsic chaperone activity, suggesting that the initial steps in energy-dependent protein degradation may be similar to those of chaperone-dependent protein folding. The classical chaperones are also required for degradation of certain proteins in vivo, but we propose below that generally they affect proteolysis indirectly by maintaining proteins in soluble forms that would otherwise aggregate and become inaccessible to proteases. In this review we present the evidence linking the activities of chaperones and proteases, and propose a general model for what can be thought of as a triage system for handling misfolded proteins in vivo, assuring swift refolding of proteins with functional potential and rapid degradation of irreversibly denatured or damaged proteins.

\section{Chaperone activities of proteases}

Energy-dependent proteases recognize and select their protein targets in an environment of other proteins that should not be degraded. They then present the proper substrates, and only the proper substrates, to the proteolytic active site. It seems reasonable to expect that protein unfolding is necessary to move a portion of the substrate into position to be cleaved. Because degradation is generally quite processive, further unfolding may be required to fully degrade the protein. Such unfolding might be considered analogous to the usual activities of classical chaperones, although in this case the result is the

${ }^{3}$ Corresponding author.

E-MAIL susang@helix.nih.gov; FAX (301) 496-3875. destruction of the target protein rather than reactivation. Therefore, we have named these protease-associated chaperone activities charonins (van Melderen et al. 1996; Maurizi et al. 1997). Chaperone activities have been demonstrated for three different families of ATP-dependent proteases: The Clp family, the AAA proteases such as $\mathrm{FtsH}$, and Lon proteases (summarized in Table 1; Horwich 1995; Gottesman 1996a; Langer and Neupert 1996; Schirmer et al. 1996). These protease families are found universally throughout both prokaryotes and eukaryotes, primarily in the cytoplasm of prokaryotes and in organelles of both lower and higher eukaryotes (see Table 1).

\section{Clp family}

The clearest examples of chaperone activities of proteases have been provided by in vitro studies of the ATPase subunits of the E. coli ClpAP and ClpXP proteases. The ClpAP protease, the first member of this family to be identified, is composed of two types of polypeptides, the ClpA ATPase and the ClpP peptidase. A number of subfamilies of closely related ATPases have also been identified, including $\mathrm{ClpX}$, which in combination with ClpP, forms a different ATP-dependent protease with a unique substrate specificity. The ClpY subfamily is closely related in sequence to $\mathrm{ClpX}$; however, it has been shown recently that $\mathrm{ClpY}$ combines with a completely different peptidase, ClpQ, to form an ATP-dependent protease (called ClpYQ or HslUV) (Kessel et al. 1996; Missiakas et al. 1996; Rohrwild et al. 1996).

Because the peptide bond cleavage activity lies in a separate polypeptide $(\mathrm{ClpP})$ from the substrate recognition component (ClpA or $\mathrm{ClpX}$ ), no proteolytic activity is displayed by the ATPase in the absence of ClpP. Through in vitro studies of the ATPase components, it has been demonstrated that both ClpA and ClpX have chaperone-like activity, and some aspects of the reaction mechanism are understood (Fig. 1). Although it has not been reported yet, it is likely that ClpY, by itself, will be found to have chaperone activity.

In a purified system, ClpA activates the bacteriophage $\mathrm{Pl}$ replication protein, RepA, for DNA binding. ClpA converts the inactive dimer of RepA into an active monomer, a remodeling activity that requires ATP hydrolysis (Wickner et al. 1994). In every respect, activa- 
Gottesman et al.

Table 1. ATP-dependent proteases

\begin{tabular}{|c|c|c|c|c|c|}
\hline \multirow[b]{2}{*}{ Protease } & \multirow[b]{2}{*}{ Occurrence $^{a}$} & \multicolumn{2}{|c|}{ Substrate } & \multirow[b]{2}{*}{ Comments } & \multirow[b]{2}{*}{ References $^{b}$} \\
\hline & & protease & chaperone & & \\
\hline \multicolumn{6}{|l|}{ Clp family } \\
\hline ClpAP & $\begin{array}{l}\text { E. coli; } \\
\text { plant chloroplasts; } \\
\text { ClpP: human } \\
\text { mitochondria }\end{array}$ & $\begin{array}{l}\text { E. coli MazE; } \\
\text { N-end rule } \beta \text {-Gal } \\
\text { fusion proteins; } \\
\text { Other } \beta \text {-Gal } \\
\text { fusions; } \\
\text { P1 RepA, casein, } \\
\text { and other proteins } \\
\text { (in vitro) }\end{array}$ & $\begin{array}{l}\text { RepA (in vitro) } \\
\text { luciferase (in vitro) }\end{array}$ & $\begin{array}{l}\text { ClpP: } 2 \text { rings of } 7 \\
\text { subunits (peptidase } \\
\text { activity only); ClpA: } 1 \\
\text { ring of } 6 \text { subunits; } 2 \\
\text { ATP-binding } \\
\text { sites/subunit } \\
\text { (ATP-dependent } \\
\text { chaperone); complex of } \\
\text { ClpP and ClpA has } \\
\text { ATP-dependent } \\
\text { protease activity }\end{array}$ & $\begin{array}{l}\text { Wickner et al. }(1994) ; \\
\text { Kessel et al. }(1995) ; \\
\text { Gottesman }(1996)\end{array}$ \\
\hline Clp XP & $\begin{array}{l}\text { E. coli; } \\
\text { ClpX: human, } \\
\text { S. cerevisiae } \\
\text { mitochondria }\end{array}$ & $\begin{array}{l}\text { E. coli RpoS; P1 Phd; } \\
\text { גO protein; } \\
\text { MuA (transposase); } \\
\text { MuC (repressor) }\end{array}$ & $\begin{array}{l}\text { MuA; } \lambda \mathrm{O} \text { protein (in } \\
\quad \text { vitro) }\end{array}$ & $\begin{array}{l}\text { ClpX: homo-oligomer; } 1 \\
\text { ATP binding } \\
\text { site/subunit } \\
\text { (ATP-dependent } \\
\text { chaperone); ClpP and } \\
\text { ClpX together have } \\
\text { ATP-dependent } \\
\text { protease activity }\end{array}$ & $\begin{array}{l}\text { Horwich (1995); } \\
\text { Levchenko et al. } \\
(1995) ; \\
\text { Wawrzynow et al. } \\
(1995,1996) ; \\
\text { Kruklitis et al. } \\
\text { (1996) }\end{array}$ \\
\hline $\begin{array}{l}\text { Clp YQ } \\
\text { (HslUV) }\end{array}$ & E. coli & casein (in vitro) & not examined & $\begin{array}{l}\text { ClpQ: } 2 \text { rings of } 6 \\
\text { subunits (peptidase } \\
\text { activity only); ClpY: } 1 \\
\text { ring of } 6 \text { or } 7 \text { subunits; } \\
\text { 1 ATP-binding } \\
\text { site/subunit (ATPase } \\
\text { activity); complex of } \\
\text { ClpQ and ClpY has } \\
\text { ATP-dependent } \\
\text { protease and peptidase } \\
\text { activities }\end{array}$ & $\begin{array}{l}\text { Missiakas et al. } \\
(1996) ; \text { Kessel et al. } \\
(1996) ; \text { Rohrwild et } \\
\text { al. }(1996)\end{array}$ \\
\hline $\begin{array}{l}\text { ClpB } \\
\text { Hsp104 (cytosol) } \\
\text { Hsp78 } \\
\text { (mitochondria) }\end{array}$ & E. coli; $S$. cerevisiae & none known & $\begin{array}{l}\text { protein aggregates; } \\
\text { RNA splicing } \\
\text { components; }\left[p s i^{+}\right] ; \\
\text {luciferase }\end{array}$ & $\begin{array}{l}1 \text { ring of } 6 \text { subunits; no } \\
\text { known } \\
\text { hetero-oligomeric } \\
\text { complexes }\end{array}$ & $\begin{array}{l}\text { Parsell et al. (1994); } \\
\text { Chernoff et al. } \\
\text { (1995); Moczko et } \\
\text { al. (1995); Vogel et } \\
\text { al. (1995); Schirmer } \\
\text { et al. (1996) }\end{array}$ \\
\hline \multicolumn{6}{|l|}{ AAA family } \\
\hline FtsH $(\mathrm{Hf} 1 \mathrm{~B})$ & E. coli; S. cerevisiae & $\begin{array}{l}\text { E. coli } \sigma^{32} ; \text { E. coli } \\
\text { SecY; } \lambda \text { cII }\end{array}$ & $\begin{array}{l}\text { membrane protein } \\
\text { complexes }\end{array}$ & $\begin{array}{l}\text { ATPase and protease } \\
\text { active sites in one } \\
\text { polypeptide; } \\
\text { homo-oligomer; } \\
\text { membrane proteins } \\
\text { with Zn active site; } \\
\text { active sites in cytosol }\end{array}$ & $\begin{array}{l}\text { Tomoyasu et al. } \\
\text { (1993, 1995); } \\
\text { Herman et al. } \\
\text { (1995); Akiyama et } \\
\text { al. }\{1996) ; \text { Shirai et } \\
\text { al. }\{1996\}\end{array}$ \\
\hline $\begin{array}{l}\text { Yta } 10 / \text { Ytal2 } \\
(\text { Afg3 }) /(\text { Rcal })\end{array}$ & $\begin{array}{l}\text { S. cerevisiae } \\
\text { mitochondria }\end{array}$ & $\begin{array}{l}\text { unassembled } \\
\text { membrane proteins }\end{array}$ & $\begin{array}{l}\text { assembly of ATP } \\
\text { synthase }\end{array}$ & $\begin{array}{l}\text { ATPase and protease } \\
\text { active sites in one } \\
\text { polypeptide; } \\
\text { hetero-oligomer; } \\
\text { mutants have } \\
\text { respiratory defects }\end{array}$ & $\begin{array}{l}\text { Pajic et al. (1994); } \\
\text { Tauer et al. (1994); } \\
\text { Arlt et al. (1996); } \\
\text { Guzelin et al. } \\
\text { (1996); Langer and } \\
\text { Neupert (1996) }\end{array}$ \\
\hline \multicolumn{6}{|l|}{ Lon family } \\
\hline Lon & E. coli & $\begin{array}{l}\text { E. coli } \mathrm{Su} 1 \mathrm{~A}_{;} \text {E. coli } \\
\text { RcsA; } \lambda \mathrm{N} \text { protein } ; \\
\text { F plasmid CcdA; } \\
\text { abnormal proteins }\end{array}$ & unknown & $\begin{array}{l}\text { multimer of identical } \\
\text { subunits; protease and } \\
\text { ATPase active sites in } \\
\text { one polypeptide }\end{array}$ & $\begin{array}{l}\text { Maurizi }(1992) ; \\
\text { Goldberg et al. } \\
(1994) ; \text { Gottesman } \\
(1996 \mathrm{a}, \mathrm{b})\end{array}$ \\
\hline Lon (PIM1) & $\begin{array}{l}\text { mammalian, } \\
\text { S. cerevisiae } \\
\text { mitochondria }\end{array}$ & $\begin{array}{l}\text { unassembled ATP } \\
\text { synthase subunits }\end{array}$ & $\begin{array}{l}\text { assembly of ATP } \\
\text { synthase in Ytal0 } \\
\text { mutants (in } \\
\text { multicopy) }\end{array}$ & $\begin{array}{l}\text { mutants accumulate } \\
\text { mitochondrial DNA } \\
\text { deletions and have } \\
\text { respiratory defects }\end{array}$ & $\begin{array}{l}\text { Suzuki et al. }(1994) ; \\
\text { Wagner et al. } \\
(1994) ; \text { Rep et al. } \\
(1996)\end{array}$ \\
\hline
\end{tabular}

a(Occurrence) organisms in which the protein, as well as the gene, have been identified and studied. The proteases found in $E$. coli are also found in many other bacteria, and those found in $S$. cerevisiae and mammals are likely to be found in all eukaryotes.

${ }^{\mathrm{b}}$ References are not all-inclusive. Emphasis is on review articles and papers demonstrating the chaperone activity of these proteases and related proteins. 


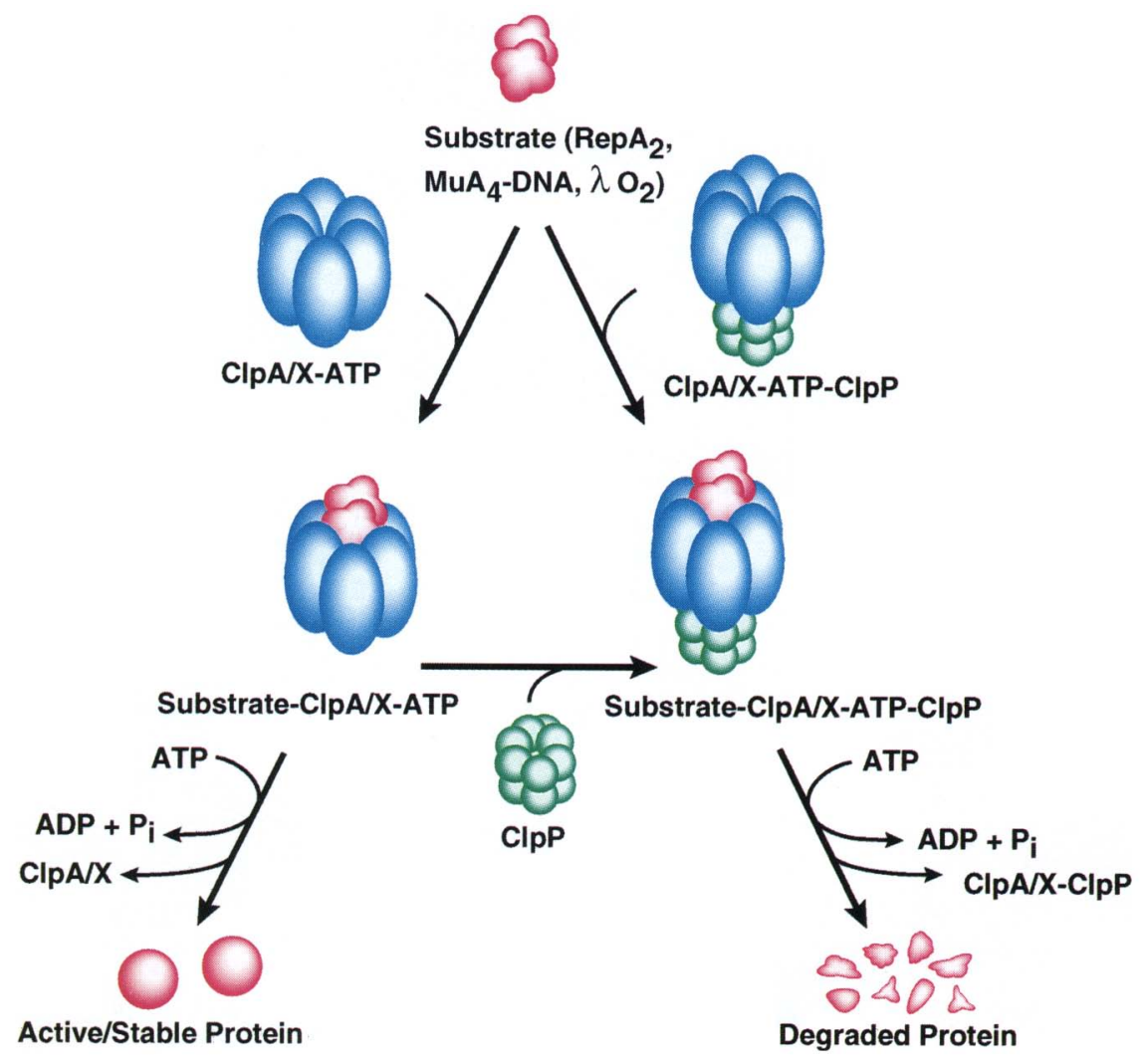

Figure 1. Chaperone activity of the Clp proteases. Substrates (red) are remodeled in ATP-dependent reactions by the ATPase components (blue), ClpA or ClpX, of the ClpAP and ClpXP proteases. In the presence of the ClpP peptidase (green), the same substrates are degraded in an ATPdependent fashion. For $\mathrm{ClpA}$ and its substrate, RepA, the initial step in the remodeling reaction is the formation of stable complexes of ClpA (six-membered rings of ClpA subunits) with inactive RepA dimers (Wickner et al. 1994; Kessel et al. 1995) containing equimolar amounts of ClpA hexamers and RepA dimers (Pak and Wickner 1997) in a reaction requiring binding of Atf only. Upon ATP hydrolysis, RepA monomers are released in a form active in DNA binding. In the alternative pathway, ClpAP [a complex of ClpA hexamers and two seven-membered rings of ClpP subunits [Kessel et al. 1995)] probably forms complexes with RepA dimers without a need for hydrolysis of the bound ATP. With ATP hydrolysis, RepA is degraded. Very likely by similar mechanisms, ClpX disassembles MuA tetramers bound to DNA (Levchenko et al. 1995) and disaggregates $\lambda O$ protein (Wawrzynow et al. 1995) and ClpXP degrades both of these substrates (Woitkowiak et al. 1993; Levchenko et al. 1995). However, the structure of $\mathrm{ClpX}$ and the intermediates in protein remodeling and degradation have not been described. tion of RepA by ClpA is identical to activation by the purified DnaJ/DnaK/GrpE chaperone system, which appears to be the chaperone system required for activation of RepA in vivo (Bukau and Walker 1989; Tilly and Yarmolinsky 1989; Wickner et al. 1991, 1992). ClpX stimulates replication of bacteriophage $\mathrm{Mu}$ by promoting the disassociation of the MuA protein from DNA (Levchenko et al. 1995; Kruklitis et al. 1996). This ClpX chaperone activity also requires ATP hydrolysis. In vivo, Mu replication is impaired in a $\operatorname{clpX}$ mutant but not in a clpP mutant, confirming that the biologically important reaction dependent on ClpX is related to its chaperone activity rather than its activity as part of the ClpXP protease (Mhammedi-Alaoui et al. 1994).

$\mathrm{ClpX}$ and ClpA also have other in vitro activities characteristic of chaperones. ClpA protects luciferase from irreversible heat inactivation, although it cannot promote reactivation of the heat-treated enzyme (Wickner et al. 1994). ClpX can prevent aggregation of $\lambda$ O protein and aid in its disaggregation (Wawrzynow et al. 1995). Some of these activities (e.g., preventing aggregation) do not require ATP hydrolysis and hence do not appear to involve active refolding but may reflect the ability of the ATPase subunit to bind to regions of unfolded or misfolded proteins.
Two close relatives of ClpA, ClpB from E. coli and Hsp104 from Saccharomyces cerevisiae, have not been implicated in proteolysis or shown to have any associated peptidase subunits but do exhibit chaperone-like activities on a variety of substrates and are necessary for thermotolerance in vivo (Squires et al. 1991; Sanchez et al. 1992; Schirmer et al. 1996). In vivo, Hsp104 functions in the reactivation of luciferase and mRNA splicing activity after heat inactivation (Parsell et al. 1994; Vogel et al. 1995). In both cases, Hsp104 acts to resolubilize protein aggregates. Another Clp ATPase, yeast mitochondrial Hsp78 (mtHSP78), provides partial redundancy with $\mathrm{mtHsp} 70$ in promoting import of mitochondrial proteins and preventing aggregation of some misfolded proteins (Schmitt et al. 1995). The explanation for this may be that $\mathrm{mtHsp} 78$ helps to maintain function and/or solubility of the mutant mtHsp70 (Moczko et al. 1995). An overlap in function has also been found for Hsp104 and some of the cytoplasmic Hsp70s of yeast (Sanchez et al. 1993|.

\section{FtsH/AAA Family}

The FtsH/AAA family of proteases are anchored to membranes but contain cytoplasmic domains with 
ATPase activity and $\mathrm{Zn}^{2+}$ metalloprotease active sites (Tomoyasu et al. 1993, 1995). In eukaryotes, these proteases are found associated with mitochondria. Mutations in Ytal0 or Yta12 (two mitochondrial FtsH-like proteins, also called Afg3 and Rcal) block both the degradation of abnormal proteins and membrane protein assembly (Pajic et al. 1994; Tauer et al. 1994). Evidence from in vivo studies suggests that these two related polypeptides assemble to form a heterooligomeric ATP-dependent protease with associated chaperone activities. Mutations in the protease active site of either subunit interfere with in vivo degradation of misfolded proteins but do not impair the function of Yta10 or Ytal2 in allowing cell growth on nonfermentable carbon sources, a measure of mitochondrial function (Arlt et al. 1996; Guzelin et al. 1996). The protease active site mutants retain the ability to promote assembly of the ATP synthase, demonstrating an in vivo chaperone-like activity that is independent of protease activity.

In E. coli, some aspects of membrane assembly and protein localization depend on FtsH in a pathway that may be independent of its degradation activity; the requirement for $\mathrm{FtsH}$ can be suppressed by overproduction of chaperones (Akiyama et al. 1994; Shirai et al. 1996). Whether this is a true chaperone activity of FtsH remains to be shown.

The ability of the Yta10/Yta12 protease complex to both promote assembly and degrade subunits of the unassembled ATP synthase leads to an interesting problem. What is the molecular mechanism underlying the decision to direct polypeptide chains into the assembly pathway or to present them for proteolysis? For proteases in which the chaperone (i.e., ClpA or $\mathrm{ClpX}$ ) and the proteolytic activity (i.e., ClpP) are on separate subunits, the chaperone component may sometimes be free of the proteolytic component and therefore able to participate independently in protein folding and assembly. For proteases in which the protease active site resides in the same polypeptide as the ATPase, two related possibilities can be considered. If cycles of substrate release and rebinding occurred before commitment to the degradation pathway, only proteins unable to reach their native state of folding and assembly (therefore no longer recognized as a substrate) would be available to be degraded. Alternatively, there may be separate sites on the chaperone portion of the protease for substrate binding, one leading to degradation and another leading to refolding. These possible mechanisms await testing.

\section{Lon family}

Lon protease is a homo-oligomer, each subunit of which carries a protease active site and an ATP-binding site consensus (Goldberg et al. 1994; Gottesman 1996a,b). It is a cytoplasmic protein in prokaryotes and a mitochondrial matrix protein in eukaryotes. Lon participates in the proteolysis of both specific protein targets (such as RcsA and SulA in E. coli) and abnormal proteins. Lon overproduction in yeast mitochondria can substitute for the FtsH-like Yta10/Yta12 protease in the assembly of membrane proteins, a function that appears to reflect chaperone activity rather than proteolysis (Rep et al. 1996). As with Yta10/Yta12, a mutation in the protease active site of the overproduced Lon also promotes membrane protein assembly. Membrane assembly is actually enhanced in this mutant. Therefore, like the Clp and AAA proteases, Lon appears to have protein remodeling activity, judging by its in vivo role in membrane assembly.

\section{Chaperone activity of proteases is important for proteolysis}

These examples suggest that the protein-binding domains of the ATP-dependent proteases can interact with substrates and promote chaperone-like remodeling/refolding of proteins. Within the Clp family, the chaperone activities show specificity. Proteins closely related to $\mathrm{ClpA}$, including ClpX and the even more closely related $\mathrm{ClpB} /$ Hsp104 proteins, cannot act on RepA (Wickner et al. 1994), and, conversely, ClpA does not disassemble MuA-DNA complexes (Levchenko et al. 1995). The specificities of the chaperone activities are mirrored by the observed substrate specificities of the ClpAP and ClpXP proteases. When ClpP is present, the chaperone substrates become substrates for proteolysis; ClpAP degrades RepA but not MuA, and ClpXP degrades $\lambda \mathrm{O}$ protein and MuA but not RepA (Gottesman et al. 1993; Woitkowiak et al. 1993; Wickner et al. 1994; Levchenko et al. 1995).

For Lon, direct evidence that unfolding is a necessary part of the proteolytic pathway comes from in vitro studies of Lon degradation of a known in vivo substrate, the 72-amino acid $\mathrm{F}$ plasmid CcdA protein and a 41-amino acid carboxy-terminal fragment of the same protein, CcdA4l (van Melderen et al. 1996). Native CcdA displays significant secondary structure (as judged by far UV circular dichroism measurements) and is degraded by Lon in an ATP hydrolysis-dependent reaction. However, heat treatment results in a loss of secondary structure in CcdA and diminishes the requirement for ATP hydrolysis for degradation. The truncated CcdA4l protein is unstructured even at ambient temperature and is degraded without ATP hydrolysis, suggesting that ATP hydrolysis is required only when unfolding is necessary (i.e., with CcdA, not CcdA41). Similarly, degradation of small polypeptides by Lon and ClpAP proteases are catalyzed without ATP hydrolysis, although degradation of larger protein substrates requires cleavable ATP /Waxman and Goldberg 1986; Maurizi 1987; Thompson and Maurizi 1994). These results suggest that unfolding of complex substrates requires the ATP-dependent chaperone activity of the protease for efficient proteolysis.

\section{Participation of classical chaperones in proteolysis}

Because protein unfolding is an essential step for proteolysis by the energy-dependent intracellular proteases, can classical chaperones provide or augment this function, and is this an important component of protein deg- 
radation in vivo? Although a coupled unfolding-degradation reaction requiring both chaperones and energy-dependent proteases has not been demonstrated in a purified in vitro system, a number of observations have suggested that classical chaperones of the Hsp70 and Hsp60 families participate in protein degradation in vivo. Unfortunately, the pleiotropy of most chaperone mutants complicates the interpretation of many in vivo experiments.

The primary observation linking chaperone activity and proteolysis is that mutations in the gene $(h t p R)$ for the general heat shock regulator of E. coli, $\mathrm{RpoH}$, can lead to significantly slowed degradation of abnormal proteins (Baker et al. 1984; Goff et al. 1984). The genes for many cellular proteases are under heat shock control, including the ATP-dependent Lon, ClpXP, FtsH, and HslUV (ClpYQ) proteases (Gottesman 1996a; Gross 1996). Although an $h t p R$ mutant would be expected to have lower expression of these proteases, the defects in proteolysis appear to be much greater than the defects in protease synthesis. Therefore, it is unlikely that decreased levels of proteases provide the full explanation for the decreased protein degradation activity in $h t p R$ mutants.

Mutations in specific chaperones (DnaK/Dna)/GrpE and GroEL/GroES) generally result in lowering the amount of protein degradation in cells but, in specific instances, can lead to increased degradation of individual substrates (Keller and Simon 1988; Straus et al. 1988; Kroh and Simon 1991; Kandror et al. 1994; Jubete et al. 1996). As mutations in dnaJ, dnaK, and grpE can lead to constitutive expression of the heat shock response and consequently to increased protease gene transcription (Gross 1996), the decreased degradation generally seen in chaperone mutants is all the more striking. Overproduction of GroEL and GroES can help protect some proteins from degradation (LaRossa and Van Dyk 1991); in other cases, they can stimulate proteolysis of a specific abnormal protein (Kandror et al. 1994), suggesting that GroEL/ GroES chaperones also function in the degradation pathway for some proteins.

Several in vitro observations have also implicated chaperones in ATP-dependent proteolysis. For example, CRAG, a hybrid abnormal protein whose degradation depends in large part on ClpP and to some extent on Lon, was found associated with GroEL and another protein suspected to have chaperone activity, trigger factor (Kandror et al. 1994, 1995). Similarly, PhoA61, a nonsecreted mutant form of alkaline phosphatase that is degraded rapidly in vivo, is found in cell extracts associated with both DnaK and to a lesser extent, Lon (Sherman and Goldberg 1991, 1992). The degree of association of CRAG with GroEL and of PhoA61 with DnaK correlates well with the rate of degradation of these proteins, suggesting that the complexes may be intermediates in the degradation pathway. The yeast cytoplasmic Dnal homolog Ydjl is also found associated with specific unstable proteins (Lee et al. 1996).

In a recent report, denatured luciferase was found to be in complexes with the eukaryotic Hsp90 chaperone,
Hsp70, p60, and other factors and could be reactivated in an ATP-dependent reaction in reticulocyte lysates (Schneider et al. 1996). When Hsp90 was inhibited (by ansamycins\}, the rate of luciferase degradation increased, whereas the rates of both luciferase release from Hsp90 and luciferase reactivation decreased. Degradation is presumably by the ubiquitin-dependent $26 \mathrm{~S}$ protease; this study suggests that in contrast to the proteases discussed above, the chaperone-bound polypeptide is the substrate for either ubiquitin-tagging or proteolysis.

\section{Quality control: participation of chaperones and proteases}

Under normal, wild-type conditions, the function of chaperones is to maximize the proper folding, refolding, and assembly of proteins, and that of proteases is to dispose of those that cannot be folded. For such a triage system to work properly, there must be stages in the process that allow a given protein to be examined for folding capability so that the appropriate pathway can be chosen. Below, we discuss the possible ways in which chaperones might affect proteolysis and whether these effects provide some type of quality control.

One could imagine that chaperones act in proteolysis to promote synthesis, assembly, or activation of the proteases themselves. This possibility has not been tested for most of the ATP-dependent proteases. In the one instance where it has been examined, for the Lon protease in E. coli, it is not the case, as the effect of a dnal mutation on the degradation of Lon substrates is substratespecific rather than protease-specific (Jubete et al. 1996).

Another possibility is that chaperones act directly and intimately in the proteolytic pathway, feeding all or many substrates to the protease. By binding to a substrate, the chaperone would tag the substrate for destruction. The protease might recognize either features of the chaperone-protein complex itself or an exposed region of the substrate made accessible by chaperone binding. In this model, the triage process for separating refoldable proteins from those that should be degraded would have to be reflected in the nature of the chaperone-substrate complex. For instance, are complexes of chaperones with "unfoldable" proteins relatively more stable, giving proteases sufficient time to interact with the chaperonebound protein? Or, are there different modes of chaperone binding to refoldable and nonrefoldable substrates, giving rise to structurally different complexes, only one of which is recognized by the protease?

Although some data support predictions of this model, others do not. The decreased degradation of abnormal proteins in chaperone mutants, reviewed above, might be interpreted as evidence for protease recognition of the substrate only in the context of the chaperone. Data showing increased degradation of Hsp90-bound luciferase (discussed above) suggest that in that system the chaperone-bound substrate may be directly presented for proteolysis (Schneider et al. 1996). A similar increase in degradation of some substrates in a dnaK756 mutant might reflect binding that mimics that of a nonrefoldable 
protein (Sherman and Goldberg 1992). However, degradation of other substrates, including abnormal proteins, is blocked rather than enhanced in the same dnaK mutant, which is inconsistent with the targeting of proteinDnaK complexes for proteolysis (Straus et al. 1988). In addition, no in vitro evidence supports the idea that binding of some (nonrefoldable) substrates to chaperones is more stable or qualitatively different from the binding of other (refoldable) substrates.

If chaperone-protein complexes are the targets for protein degradation, one might also expect specificity in the coupling of chaperones and proteases and a requirement for the specific chaperone for efficient proteolysis by a given protease. This is certainly not true for all degradation. In vivo, dnaJ is necessary for Lon-dependent degradation of abnormal proteins and RcsA, whereas two other substrates, SulA and $\lambda N$ protein, are degraded normally in dnaJ mutants (Jubete et al. 1996). In vitro, Lon can degrade $\lambda \mathrm{N}$ protein, CcdA, and SulA; ClpXP can degrade $\mathrm{MuA}$ and $\lambda \mathrm{O}$ protein; and FtsH can degrade $\sigma^{32}$ without the participation of chaperones (Maurizi 1987; Wojtkowiak et al. 1993; Levchenko et al. 1995; Sonezaki et al. 1995; Tomoyasu et al. 1995; van Melderen et al. 1996). Therefore, this model would also require that the chaperone requirement for proteolysis be substrate specific, and the direct participation of chaperones in proteolysis cannot be a prerequisite for all protein degradation. There may be some specific substrates for which interaction with a chaperone is essential for degradation, but efforts to demonstrate this in vitro, for example, by including chaperones in degradation reactions in vitro, have been unsuccessful thus far (Sherman and Goldberg 1992).

\section{A kinetic model for protein triage}

The bulk of the available evidence supports an indirect role for chaperones in proteolysis, reflecting the ability of chaperones to maintain abnormal proteins, potential substrates for degradation, in a soluble state. In this model (outlined in Fig. 2), chaperones assist in generating and stabilizing a population of soluble, misfolded, non-native forms of polypeptides by binding and releasing misfolded or unassembled proteins. This pool also will include non-native forms arising from new synthesis of some normal as well as abnormal proteins and from heat or chemical denaturation. The fates of these misfolded proteins, and therefore quality control, would

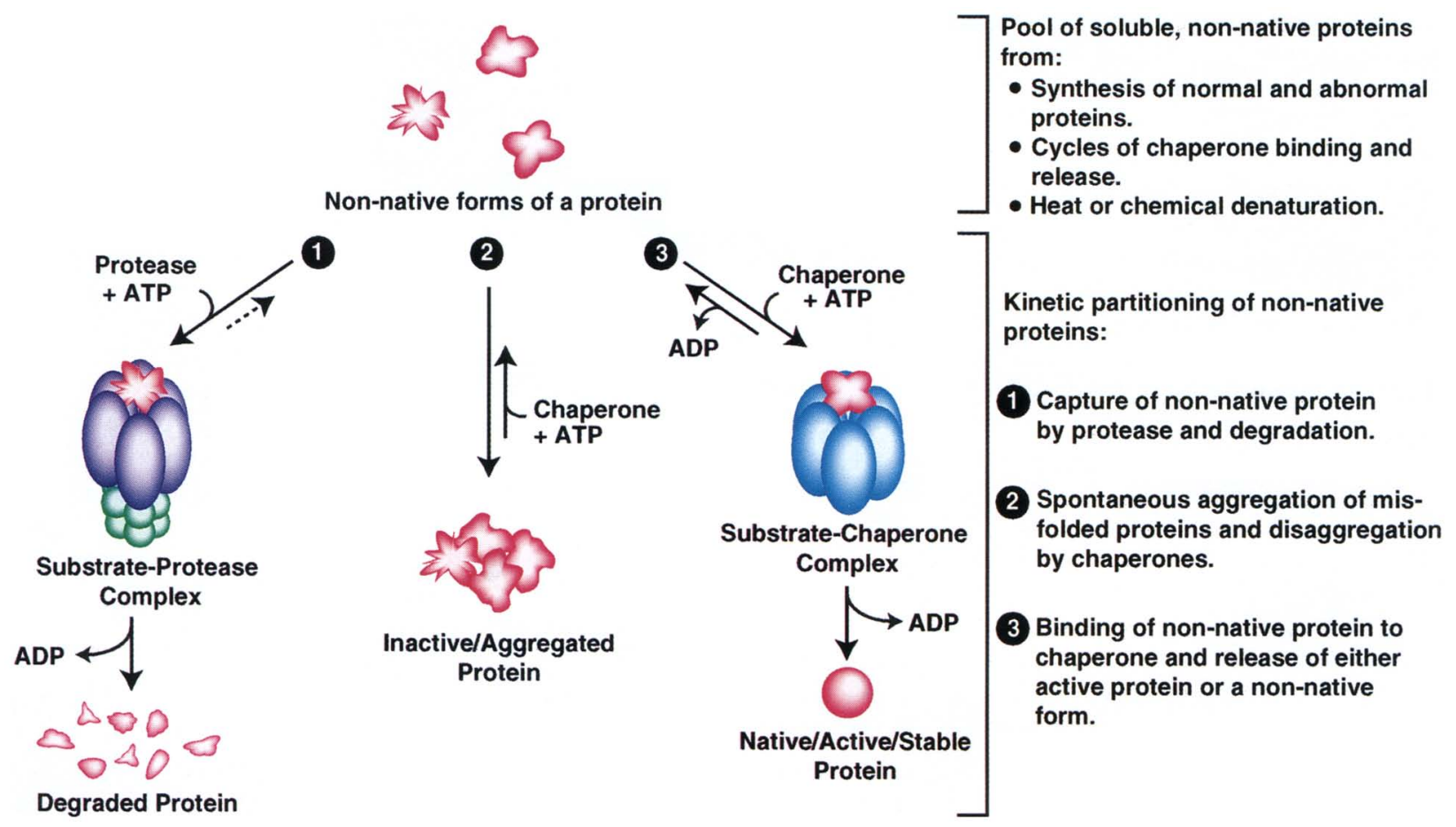

Figure 2. A kinetic model for protein triage. Polypeptides in unfolded and other non-native forms (shown in red) may interact with a number of other cellular proteins. The relative rates at which these occur will determine the ultimate fate of the protein. (1) They may be recognized by proteases (shown in purple and green), almost always leading to degradation; (2) they may aggregate with themselves or other proteins; reversal of aggregation may in some cases be promoted by chaperones, thus returning these polypeptides to the pool of soluble proteins; or (3) they may bind chaperones (shown in blue). Release from the chaperone may either return the protein to the soluble pool of non-native forms or may result in an active/refolded protein that is no longer a substrate for either protease or chaperone binding. In the absence of chaperones, a competition between the rates of aggregation and degradation will determine the fate of the polypeptide. Naturally unstable proteins obey similar rules; relative rates of degradation and aggregation will determine the sensitivity of degradation to chaperones. We would predict that in the eukaryotic cytoplasm, the ubiquitin ligase systems play the primary recognition role akin to that of the protease shown here. 
reflect the relative affinities of non-native forms for proteases, chaperones, and other cellular components and the relative rates of degradation, aggregation, and folding (Fig. 2, pathways 1, 2, and 3, respectively). If the native form of a protein were reached (and the hydrophobic regions were buried), either spontaneously or via chaperone binding and release, the protein would no longer be recognized by chaperones or proteases as an appropriate target. Alternatively, some of the non-native structures might have higher affinity for specific proteases than for chaperones, thereby directing the polypeptide down the pathway of degradation. Other non-native, misfolded forms (presumably with very large hydrophobic regions exposed) might aggregate rapidly and become inaccessible to either proteases or to chaperones. The bulk of the current data supports this model of kinetic partitioning of substrates.

If this kinetic model is reliable, in the absence of chaperones there should be a significant increase in aggregated proteins in vivo and aggregation should correlate with decreased degradation. These predictions seem to be consistent with many experimental findings. Abnormal proteins have been found to aggregate in the absence of DnaJ, and even newly made normal proteins appear in aggregates in cells mutant in both the GroEL/GroES and DnaK/DnaJ/GrpE chaperone systems /Gragerov et al. 1992; Jubete et al. 1996). In cells devoid of DnaJ, the Lon substrate RcsA aggregates and its degradation by Lon is slowed. Degradation of another Lon substrate, SulA, occurs at the same rate in the presence or absence of DnaJ in lon $^{+}$cells, but degradation in the absence of Lon shows significant dependence on DnaJ. In lon dnal double mutants, SulA is found in an insoluble fraction, suggesting that the protein aggregates more rapidly than it is attacked by other proteases in the cell (Jubete et al. 1996). In eukaryotes, mutations in mitochondrial DnaK and DnaJ homologs (mtHsp70 and Mdj1) slow the degradation of misfolded dihydrofolate reductase (DHFR), which is dependent on the Lon (PIM1) protease; the DHFR is found in an aggregated state in the chaperone mutants (Wagner et al. 1994). Thus, in several cases in which chaperone mutants have been shown to slow degradation, the undegraded substrates are found to be aggregated.

An important additional in vivo activity of classical chaperones that can have profound effects on protein degradation is the participation of chaperones in assembly of multiprotein complexes. In many of these cases, the components of the multimeric complexes are totally stable when properly assembled but are subject to rapid degradation when unassembled, either because components are not present in the proper stoichiometry /which we have referred to as "proteins without partners" (Gottesman 1989; Gottesman and Maurizi 1992) or because defects in chaperone activity slow the assembly process and therefore allow a switch in the kinetic hierarchy, as shown in Figure 2. For instance, degradation of the SecY protein in $E$. coli by FtsH is observed when the proteins with which it normally assembles are not available (Kihara et al. 1995). Similarly, subunits of the mitochon- drial ATP synthases that depend on the chaperone activity of the AAA protein family for assembly become subject to degradation (by the same protease) when assembly is blocked by incorrect subunit stoichiometery (Pajic et al. 1994; Tauer et al. 1994; Guzelin et al. 1996). In these cases, degradation outpaces aggregation. We propose that in other cases of failed assembly, degradation is not observed because aggregation outpaces degradation.

\section{Conclusions}

The initial steps in the pathway of protein degradation by energy-dependent proteases show many of the characteristics of chaperone-dependent protein remodeling, and, in fact, ATP-dependent proteases have intrinsic protein remodeling activity. This overlap in function probably reflects the requirement for energy-dependent proteases to recognize and bind non-native proteins and unfold them sufficiently to allow them entry into the proteolytic active site, just as classical chaperones must recognize and bind non-native proteins in the pathway of folding or remodeling. The recognition of the unfolding activity of proteases raises the question of whether classical chaperones play a role in presenting substrates to the protease. We suggest that this role is indirect and that chaperones generally contribute to the rapid degradation of abnormal proteins by maintaining them in a relatively soluble and therefore protease-accessible form. The similiarities between the early stages of energy-dependent proteolysis and chaperone-mediated protein folding suggest that our understanding of each will be enriched by a study of the other.

\section{References}

Akiyama, Y., T. Ogura, and K. Ito. 1994. Involvement of FtsH in protein assembly into and through the membrane. I. Mutations that reduce retention efficiency of a cytoplasmic reporter. I. Biol. Chem. 269: 5218-5224.

Akiyama, Y., A. Kihara, H. Tokuda, and K. Ito. 1996. FtsH (HflB) is an ATP-dependent protease selectively acting on SecY and some other membrane proteins. I. Biol. Chem. 271:3119631201 .

Arlt, H., R. Tauer, H. Feldmann, W. Neupert, and T. Langer. 1996. The Yta10-12 complex, an AAA protease with chaperone-like activity in the inner membrane of mitochondria. Cell 85: 875-885.

Baker, T.A., A.D. Grossman, and C.A. Gross. 1984. A gene regulating the heat shock response in $E$. coli affects proteolysis. Proc. Natl. Acad. Sci. 81: 6779-6783.

Bukau, B. and G.C. Walker. 1989. AdnaK52 mutants of Escherichia coli have defects in segregation and plasmid maintenance at normal temperatures. J. Bacteriol. 171: 6030-6038.

Chernoff, Y.O., S.L. Lindquist, B. Ono, S.G. Inge-Vechtomov, and S.W. Liebman. 1995. Role of the chaperone protein Hsp104 in propagation of the yeast prion-like facter $\left[p s i^{+}\right]$. Science 268: 881-884.

Goff, S.A., L.P. Casson, and A.L. Goldberg. 1984. Heat shock regulatory gene $h t p R$ influences rates of protein degradation and expression of the lon gene in Escherichia coli. Proc. Natl. Acad. Sci. 81: 6647-6651.

Goldberg, A., R.P. Morschell, C.H. Chung, and M.R. Maurizi. 
1994. ATP-dependent protease La (lon) from Escherichia coli. Methods Enzymol. 244: 350-375.

Gottesman, S. 1989. Genetics of proteolysis in Escherichia coli. Annu. Rev. Genet. 23: 163-198.

- 1996a. Proteases and their targets in Escherichia coli. Annu. Rev. Genet. 30: 465-506.

- 1996b. Roles for energy-dependent proteases in regulatory cascades. In Regulation of gene expression in Escherichia coli, (ed. E.C.C. Lin and A.S. Lynch) pp. 503-519. R.G. Landes Co., Austin, TX.

Gottesman, S. and M.R. Maurizi. 1992. Regulation by proteolysis: Energy-dependent proteases and their targets. Microbiol. Rev. 56: 592-621.

Gottesman, S., W.P. Clark, V. de Crecy-Lagard, and M.R. Maurizi. 1993. ClpX, an alternative subunit for the ATPdependent Clp protease of Escherichia coli. J. Biol. Chem. 268: 22618-22626.

Gragerov, A., E. Nudler, N. Komissarova, G.A. Gaitanaris, M.E. Gottesman, and V. Nikiforov. 1992. Cooperation of GroEL/ GroES and DnaK/DnaJ heat shock proteins in preventing protein misfolding in Escherichia coli. Proc. Natl. Acad. Sci. 89: 10341-10344.

Gross, C. 1996. Function and regulation of the heat shock proteins. In Escherichia coli and Salmonella typhimurium (ed. F.C. Neidhardt, R. Curtiss III, J.L. Ingraham, E.C.C. Lin, J.K.B. Low, B. Magasanik, W.S. Reznikoff, M. Riley, M. Schaechter and H.E. Umbarger|, pp. 1382-1399. American Society for Microbiology, Washington, D.C.

Guzelin, E., M. Rep, and L.A. Grivell. 1996. Afg3p, a mitochondrial ATP-dependent metalloprotease, is involved in degradation of mitochondrially-encoded Cox1, Cox3, Cob, Su6, Su8 and Su9 subunits of the inner membrane complexes III, IV and V. FEBS Lett. 381: 42-46.

Herman, C., D. Thévenet, R. D'Ari, and P. Bouloc. 1995. Degradation of $\sigma 32$, the heat shock regulator in Escherichia coli, is governed by HflB. Proc. Natl. Acad. Sci. 92: 3516-3520.

Horwich, A.L. 1995. Resurrection or destruction. Curr. Biol. 5: 455-458.

Jubete, Y., M.R. Maurizi, and S. Gottesman. 1996. Role of the heat shock protein DnaJ in the Lon-dependent degradation of naturally unstable proteins. J. Biol. Chem. 271: 3079830803.

Kandror, O., L. Busconi, M. Sherman, and A.L. Goldberg. 1994. Rapid degradation of an abnormal protein in Escherichia coli involves the chaperones GroEL and GroES. I. Biol. Chem. 269: 23575-23582.

Kandror, O., M. Sherman, M. Rhode, and A.L. Goldberg. 1995. Trigger factor is involved in GroEL-dependent protein degradation in Escherichia coli and promotes binding of GroEL to unfolded proteins. EMBO J. 14: 6021-6027.

Keller, J.A. and L.D. Simon. 1988. Divergent effects of a dnaK mutation on abnormal protein degradation in Escherichia coli. Mol. Microbiol. 2: 31-41.

Kessel, M., M.R. Maurizi, B. Kim, E. Kocsis, B.L. Trus, S.K. Singh, and A.C. Steven. 1995. Homology in structural organization between $E$. coli ClpAP protease and the eukaryotic 26S proteasome. J. Mol. Biol. 250: 587-594.

Kessel, M., W.-F. Wu, S. Gottesman, E. Kocsis, A.C. Steven, and M.R. Maurizi. 1996. Six-fold rotational symmetry of ClpQ, the E. coli homolog of the $20 \mathrm{~S}$ proteasome, and its ATPdependent activator, ClpY. FEBS Lett. 398: 274-278.

Kihara, A., Y. Akiyama, and K. Ito. 1995. FtsH is required for proteolytic elimination of uncomplexed forms of SecY, an essential protein translocase subunit. Proc. Natl. Acad. Sci. 92: 4532-4536.

Kroh, H.E. and L.D. Simon. 1991. Increased ATP-dependent pro- teolytic activity in Lon-deficient Escherichia coli strains lacking the DnaK protein. I. Bacteriol. 173: 2691-2695.

Kruklitis, R., D.J. Welty, and H. Nakai. 1996. ClpX protein of Escherichia coli activates bacteriophage $\mathrm{Mu}$ transposase in the strand transfer complex for initiation of Mu DNA synthesis. $E M B O$ J. 15: 935-944.

LaRossa, R.A. and T.K. Van Dyk. 1991. Physiological roles of the DnaK and GroE stress proteins: Catalysts of protein folding or macromolecular sponges? Mol. Microbiol. 5: 529-534.

Langer, T. and W. Neupert. 1996. Regulated protein degradation in mitochondria. Experientia 52: 1069-1076.

Lee, D.H., M.Y. Sherman, and A.L. Goldberg. 1996. Involvement of the molecular chaperone Ydjl in the ubiquitin-dependent degradation of short-lived and abnormal proteins in Saccharomyces cerevisiae. Molec. Cell. Biol. 16: 4773-4781.

Levchenko, I., L. Luo, and T.A. Baker. 1995. Disassembly of the $\mathrm{Mu}$ transposase tetramer by the ClpX chaperone. Genes \& Dev. 9: 2399-2408.

Maurizi, M.R. 1987. Degradation in vitro of bacteriophage lambda $\mathrm{N}$ protein by Lon protease from Escherichia coli. J. Biol. Chem. 262: 2696-2703.

- 1992. Proteases and protein degradation in Escherichia coli. Experientia 48: 178-201.

Maurizi, M.R., S. Wickner, and S. Gottesman. 1997. Chaperones and charonins: Protein unfolding enzymes and proteolysis. In Molecular biology of chaperones and protein catalysts (ed. B. Bukau), Harwood Academic Publishers, Amsterdam, The Netherlands. (In Press).

Mhammedi-Alaoui, A., M. Pato, M.-J. Gamma, and A. Toussaint. 1994. A new component of bacteriophage $\mathrm{Mu}$ replicative transposition machinery: The Escherichia coli ClpX protein. Mol. Microbiol. 11: 1109-1116.

Missiakas, D., F. Schwager, J.-M. Betton, C. Georgopoulos, and S. Raina. 1996. Isolation and characterization of HslV HslU (ClpQ ClpY) proteins involved in overall proteolysis of misfolded proteins in E. coli. EMBO I. 15: 6899-6909.

Moczko, M., B. Schonfisch, W. Voos, N. Pfanner, and J. Rassow. 1995. The mitochondrial ClpB homolog Hsp78 cooperates with matrix $\mathrm{Hsp} 70$ in maintenance of mitochondrial function. J. Mol. Biol. 254: 538-543.

Pajic, A., R. Tauer, H. Feldmann, W. Neupert, and T. Langer. 1994. Yta10p is required for the ATP-dependent degradation of polypeptides in the inner membrane of mitochondria. FEBS Lett. 353: 201-206.

Pak, M. and S. Wickner. 1997. Mechanism of protein remodeling by ClpA chaperone. Proc. Natl. Acad. Sci. 94: (in press).

Parsell, D.A., A.S. Kowal, M.A. Singer, and S. Lindquist. 1994. Protein disaggregation mediated by heat-shock protein Hsp104. Nature 372: 475-478.

Rep, M., J.M. van Dijl, K. Suda, G. Schatz, L.A. Grivell, and C.K. Suzuki. 1996. Promotion of mitochondrial membrane complex assembly by a proteolytically inactive yeast Lon. Science 274: 103-106.

Rohrwild, M., O. Coux, H.-C. Huang, R.P. Moerschell, S.J. Yoo, J.H. Seol, C.H. Chung, and A.L. Goldberg. 1996. HslV-HslU: A novel ATP-dependent protease complex in Escherichia coli related to the eukaryotic proteasome. Proc. Natl. Acad. Sci. 93: 5808-5813.

Sanchez, Y., D.A. Parsell, J. Taulien, J.L. Vogel, E.A. Craig, and S. Lindquist. 1993. Genetic evidence for a functional relationship between Hsp104 and Hsp70. J. Bacteriol. 175: 64846491.

Sanchez, Y., J. Taulien, K.A. Borkovich, and S. Lindquist. 1992. Hspl04 is required for tolerance to many forms of stress. EMBO I. 11: 2357-2364.

Schirmer, E.C., J.R. Glover, M.A. Singer, and S. Lindquist. 1996. 
HSP100/Clp proteins: A common mechanism explains diverse functions. Trends Biochem. Sci. 21: 289-296.

Schmitt, M., W. Neupert, and T. Langer. 1995. Hsp78, a Clp homologue within mitochondria, can substitute for chaperone functions of mt-hsp70. EMBO J. 14: 3434-3444.

Schneider, C., L. Sepp-Lorenzino, E. Nimmesgern, O. Ouerfelli, S. Danishefsky, N. Rosen, and F.U. Hartl. 1996. Pharmacologic shifting of a balance between protein refolding and degradation mediated by Hsp90. Proc. Nat1. Acad. Sci. 93: 14536-14541.

Sherman, M.Y. and A.L. Goldberg. 1991. Formation in vitro of complexes between an abnormal fusion protein and the heat shock proteins from Escherichia coli and yeast mitochondria. J. Bacteriol. 173: 7249-7256.

1992. Involvement of the chaperonin dnaK in the rapid degradation of a mutant protein in Escherichia coli. EMBO J. 11: $71-77$.

Shirai, Y., Y. Akiyama, and K. Ito. 1996. Suppression of $f t s H$ mutant phenotypes by overproduction of molecular chaperones. J. Bacteriol. 178: 1141-1145.

Sonezaki, S., Y. Ishii, K. Okita, T. Sugino, A. Kondo, and Y. Kato. 1995. Overproduction and purification of SulA fusion protein in Escherichia coli and its degradation by Lon protease in vitro. Appl. Microbiol. Biotechnol. 43: 304-309.

Squires, C.L., S. Pedersen, B.M. Ross, and C. Squires. 1991. ClpB is the Escherichia coli heat shock protein F84.1. J. Bacteriol. 173: 4254-4262.

Straus, D.B., W.A. Walter, and C. Gross. 1988. Escherichia coli heat shock gene mutants are defective in proteolysis. Genes \& Dev. 2: 1851-1858.

Suzuki, C.K., K. Suda, N. Wang, and G. Schatz. 1994. Requirement for the yeast gene $L O N$ in intramitochondrial proteolysis and maintenance of respiration. Science 264: 273-276.

Tauer, R., G. Mannhaupt, R. Schnall, A. Pajic, T. Langer, and H. Feldmann. 1994. Yta10p, a member of a novel ATPase family in yeast, is essential for mitochondrial function. FEBS Lett. 353: $197-200$.

Thompson, M.W. and M.R. Maurizi. 1994. Activity and specificity of Escherichia coli ClpAP protease in cleaving model peptide substrates. J. Biol. Chem. 269: 18201-18208.

Tilly, K. and M. Yarmolinsky. 1989. Participation of Escherichia coli heat shock proteins DnaJ, DnaK, and GrpE in Pl plasmid repression. J. Bacteriol. 171: 6025-6029.

Tomoyasu, T., T. Yuki, S. Morimura, H. Mori, K. Yamanaka, H. Niki, S. Hiraga, and T. Ogura. 1993. The Escherichia coli $\mathrm{FtsH}$ protein is a prokaryotic member of a protein family of putative ATPases involved in membrane functions, cell cycle control, and gene expression. I. Bacteriol. 175: 13441351.

Tomoyasu, T., J. Gamer, B. Bukau, M. Kanemori, H. Mori, A.J. Rutman, A.B. Oppenheim, T. Yura, K. Yamanaka, H. Niki, S. Hiraga, and T. Ogura. 1995. Escherichia coli FtsH is a membrane-bound, ATP-dependent protease which degrades the heat-shock transcription factor $\sigma^{32}$. EMBO J. 14: 2551-2560.

van Melderen, L., M.H.D. Thi, P. Lecchi, S. Gottesman, M. Couturier, and M.R. Maurizi. 1996. ATP-dependent degradation of CcdA by Lon protease: Effects of secondary structure and heterologous subunit interactions. J. Biol. Chem. 271: 27730-27738.

Vogel, J.L., D.A. Parsell, and S. Lindquist. 1995. Heat-shock proteins Hspl04 and Hsp70 reactivate mRNA splicing after heat inactivation. Curr. Biol. 5: 306-317.

Wagner, I., H. Arlt, L. Van Dyck, T. Langer, and W. Neupert. 1994. Molecular chaperones cooperate with PIMl protease in the degradation of misfolded proteins in mitochondria. EMBO T. 13: 5135-5145.
Wawrzynow, A., D. Wojtkowiak, J. Marzsalek, B. Banecki, M. Jonsen, B. Graves, C. Georgopoulos, and M. Zylicz. 1995. The ClpX heat-shock protein of Escherichia coli, the ATPdependent substrate specificity component of the ClpP-ClpX protease, is a novel molecular chaperone. EMBO F. 14: 18671877.

Wawrzynow, A., B. Banecki, and M. Zylicz. 1996. The Clp ATPases define a novel class of molecular chaperones. Mol. Microbiol. 21: 895-899.

Waxman, L. and A.L. Goldberg. 1986. Selectivity of intracellular proteolysis: Protein substrates activate the ATP-dependent protease (La). Science 232: 500-503.

Wickner, S., J. Hoskins, and K. McKenney. 1991. Monomerization of RepA dimers by heat shock proteins activates binding to DNA replication origin. Proc. Nat1. Acad. Sci. 88: 79037907.

Wickner, S., D. Skowyra, J. Hoskins, and K. McKenney. 1992. DnaJ, DnaK, and GrpE heat shock proteins are required in oriP1 DNA replication solely at the RepA monomerization step. Proc. Natl. Acad. Sci. 89: 10345-10349.

Wickner, S., S. Gottesman, D. Skowyra, J. Hoskins, K. McKenney, and M.R. Maurizi. 1994. A molecular chaperone, ClpA, functions like DnaK and DnaJ. Proc. Natl. Acad. Sci. 91: $12218-12222$.

Wojtkowiak, D., C. Georgopoulos, and M. Zylicz. 1993. ClpX, a new specificity component of the ATP-dependent Escherichia coli Clp protease, is potentially involved in $\lambda$ DNA replication. J. Biol. Chem. 268: 22609-22617. 


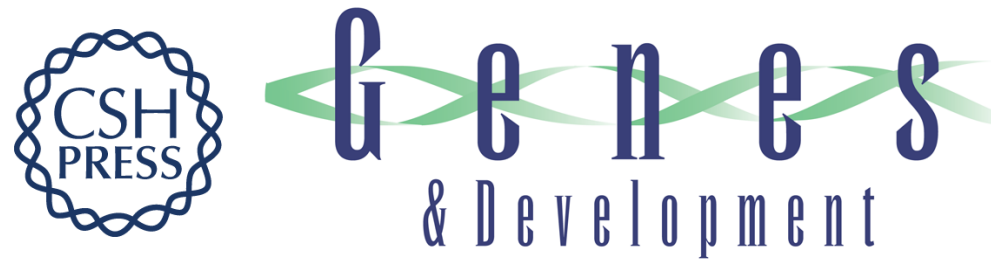

\section{Protein quality control: triage by chaperones and proteases.}

S Gottesman, S Wickner and M R Maurizi

Genes Dev. 1997, 11:

Access the most recent version at doi:10.1101/gad.11.7.815 $\begin{array}{ll}\text { References } & \begin{array}{l}\text { This article cites } 65 \text { articles, } 33 \text { of which can be accessed free at: } \\ \text { http://genesdev.cshlp.org/content/11/7/815.full.html\#ref-list-1 }\end{array}\end{array}$

License

Email Alerting

Receive free email alerts when new articles cite this article - sign up in the box at the top Service right corner of the article or click here.

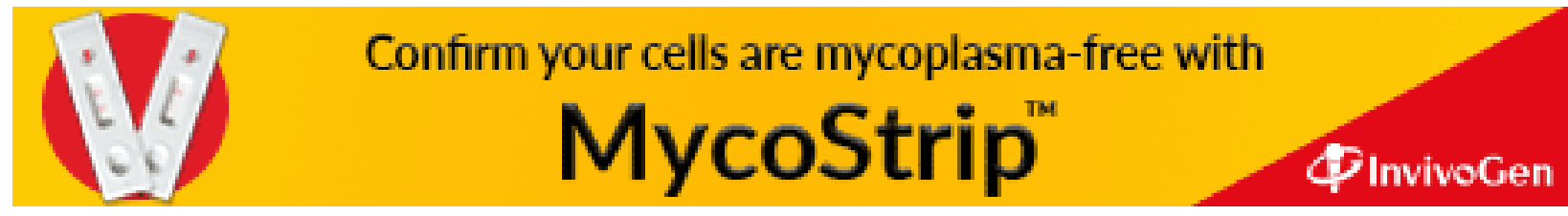

